\section{OROFACIAL CLEFTS AND ASSOCIATED CARDIAC ANOMALIES: THE 18 YEARS EXPERIENCE OF A MULTIDISCIPLINARY GROUP IN A TERTIARY HOSPITAL IN PORTUGAL}

J. Miranda ${ }^{1}$, L. Correia-Costa ${ }^{1}$, S. Corujeira ${ }^{1}$, M.J. Baptista ${ }^{2}$, A. Maia ${ }^{1}$, Cleft Lip and Palate Multidisciplinary Group at Hospital S. João, Porto-Portugal

${ }^{1}$ Serviço de Pediatria, ${ }^{2}$ Serviço de Cardiologia Pediátrica, Hospital S Joao, Porto, Portugal

Introduction: Orofacial clefts are a heterogeneous group of disorders arising in about 1.7/1000 newborns. They can occur with other congenital anomalies, including heart disease.

Aim: To describe a population with orofacial clefts and associated cardiac anomalies.

Methods: Retrospective study of patients that attended the Cleft Lip and Palate Multidisciplinary Group at Hospital S. João, Porto-Portugal. Medical records from January-1992 through December-2009 were reviewed. Patients were divided in four groups: cleft lip (CL), cleft lip and palate $(C L / P)$, isolated cleft palate (CP) and atypical cleft (AC). Further categorization included sex, affected relatives, associated congenital anomalies and syndromes.

Results: Of the 340 patients included, 54 (15.9\%) presented with cardiac anomalies. Of those with orofacial cleft and cardiac anomalies $55.6 \%$ were males and $11.1 \%$ had known affected relatives; $59.3 \%$ had $\mathrm{CP}, 27.8 \%$ had $\mathrm{CL} / \mathrm{P}, 11.1 \%$ had $\mathrm{CL}$ and $1.9 \%$ had AC. CP was the most common cleft among patients with cardiac anomaly $(p<0.05)$. Additional congenital anomalies were found in $75.9 \%$ of patients, facial defects, central nervous system, renal and skeletal malformations were the most common. A recognizable syndrome was identified in $63 \%$, Pierre-Robin $(n=14)$ and $22 q 11.2$ microdelection $(n=9)$ syndromes being the most common. Both, additional congenital anomalies and recognizable syndromes were significantly more common in patients with cardiac conditions $(p<0.05)$. The most commonly recorded cardiac anomalies were ventricular septal defect $(n=19)$, atrial septal defect $(n=17)$ and Fallot's Tetralogy $(n=6)$.

Conclusion: Due to the high prevalence of cardiac anomalies, a routine echocardiographic and electrocardiographic screening should be considered in all cleft patients.

\section{POLYMORPHISMS IN UGT1A1 GENE AMONG NORTH INDIAN NEONATES PRESENTING WITH UNCONJUGATED HYPERBILIRUBINEMIA}

\author{
R. Rathi ${ }^{1}$, S. Aggarwal ${ }^{2}$, P. Kumar², N. Khullar ${ }^{3}$, \\ R. Prasad ${ }^{1}$
}

${ }^{1}$ Biochemistry, Post Graduate Institute of Medical Education and Research, ${ }^{2} P$ ediatrics, PGIMER, ${ }^{3}$ Biotechnology, Panjab University, Chandigarh, India

Objective: Genetic factors are implicated in pathogenesis of neonatal hyperbilirubinemia. The present study was conducted to determine the frequency of (TA)n promoter polymorphism and Gly71Arg mutation in UGT1A1 gene in North Indian neonates $\geq 35$-week gestation presenting with STB $\geq 18 \mathrm{mg} / \mathrm{dL}$ and to study the interaction among the presence of UGT1A1 gene polymorphisms, G6PD gene mutations, and peak STB levels.

Methods: In addition to routine tests for jaundice evaluation, DNA was isolated for detection of (TA) n promoter polymorphism, Gly71Arg mutation in bilirubin UGT1A1 gene and G6PD Mediterranean and Orissa mutations. The number of TA repeats was assessed by a PCR-SSCP analysis and Gly71Arg mutation was detected by PCR-RFLP. Results were confirmed by DNA sequencing in 45 and 50 samples respectively. 127 neonates were enrolled (77 hyperbilirubinemics, 50 controls).

Results: The incidence of (TA) $n$ polymorphism was higher in babies with hyperbilirubinemia $[89.6 \%$ vs. $50 \%$, OR $8.63(95 \% \mathrm{Cl}, 3.2-24.1)]$. Gly71Arg mutation was not found either in hyperbilirubinemics or controls. Sequencing revealed a novel polymorphism (Ala72Pro) at codon 72 of exon 1 in 21 hyperbilirubinemics and 29 controls. Presence of variant (TA)n promoter (adjusted OR, 10.6; 95\% Cl, 3.3-34.2), G6PD deficiency (adjusted OR, 20.6; $95 \% \mathrm{Cl}, 3.6-117.3$ ), and history of jaundice in sibling requiring phototherapy (adjusted OR, 12.6; $95 \% \mathrm{CI}$, 1.1-141.6) were independent risk factors for bilirubin levels $\geq 18 \mathrm{mg} / \mathrm{dL}$.

Conclusion: (TA)n promoter polymorphism of bilirubin UGT1A1 gene was significantly associated with hyperbilirubinemia in term and near-term neonates. The effect of novel Ala72Pro mutation on mRNA and protein expression needs to be explored. 